\title{
Haematopoietic stem cell transplantation as first-line treatment in myeloma: a global perspective of current concepts and future possibilities
}

\author{
Catriona Elizabeth Mactier, ${ }^{1}$ Md Serajul Islam ${ }^{1,2}$ \\ 'Department of Haematology, Lewisham University Hospital, London; \\ ${ }^{2}$ Department of Haematology \& Stem cell Transplant, Guy's and St Thomas' Hospital, London, UK
}

\begin{abstract}
Stem cell transplantation forms an integral part of the treatment for multiple myeloma. This paper reviews the current role of transplantation and the progress that has been made in order to optimize the success of this therapy. Effective induction chemotherapy is important and a combination regimen incorporating the novel agent bortezomib is now favorable. Adequate induction is a crucial adjunct to stem cell transplantation and in some cases may potentially postpone the need for transplant. Different conditioning agents prior to transplantation have been explored: high-dose melphalan is most commonly used and bortezomib is a promising additional agent. There is no well-defined superior transplantation protocol but single or tandem autologous stem cell transplantations are those most commonly used, with allogeneic transplantation only used in clinical trials. The appropriate timing of transplantation in the treatment plan is a matter of debate. Consolidation and maintenance chemotherapies, particularly thalidomide and bortezomib, aim to improve and prolong disease response to transplantation and delay recurrence. Prognostic factors for the outcome of stem cell transplant in myeloma have been highlighted.
\end{abstract}

Correspondence: Serajul Islam, Guy's and St Thomas NHS Foundation Trust, Great Maze Pond, London, SE1 7RH, UK.

Tel. +44.07769580452 - Fax: 02083333006.

E-mail: serajul@doctors.org.uk

Key words: myeloma, stem cell transplantation, autologous, melphalan, bortezomib.

Contributions: both the authors were involved in manuscript approval; MS was responsible for the conception of the article; CEM and MSI were involved in the design of the manuscript, reviewed the literature and were responsible for writing the manuscript.

Conflict of interests: the authors declare no conflict of interests.

Received for publication: 6 March 2012.

Revision received: 15 June 2012.

Accepted for publication: 15 June 2012.

This work is licensed under a Creative Commons Attribution NonCommercial 3.0 License (CC BY-NC 3.0).

(O) Copyright C.E. Mactier and M.S. Islam, 2012

Licensee PAGEPress, Italy

Oncology Reviews 2012; 6:e14

doi:10.4081/oncol.2012.e14
Despite good responses to chemotherapy and transplantation, the problem of disease recurrence persists. Thus, there is still much room for improvement. Treatments which harness the graft-versus-myeloma effect may offer a potential cure for this disease. Trials of novel agents are underway, including targeted therapies for specific antigens such as vaccines and monoclonal antibodies.

\section{Introduction}

Multiple myeloma (MM) is a plasma cell disorder that usually involves the elderly. Approximately $65 \%$ of patients are over 65 years of age $^{1}$ and age is an independent prognostic parameter for treatment outcome of MM. ${ }^{2}$ Myeloma in patients under 50 years of age has more favorable characteristics and shows better survival; an analysis of 10,549 patients from the International Myeloma Working Group (IMWG) provides important eligibility criteria for high-dose therapy (HDT) with autologous hematopoietic stem cell transplantation (ASCT). ${ }^{2}$

The outcome of MM patients treated with conventional therapy is usually unsatisfactory with poor long-term survival. There is sufficient evidence available to establish complete response (CR) as an endpoint of treatment efficacy. ${ }^{3-5}$ Before the introduction of novel immunomodulatory drugs such as thalidomide and lenalidomide, and proteasome inhibitor bortezomib, the CR rate after induction therapy including conventional chemotherapy (CCT) was less than $10 \%{ }^{6}$ Therefore, HDT and ASCT were integrated to increase the response rate.

ASCT has been an integral component of up-front therapy for younger MM patients for more than two decades and this has, at least in part, contributed to the improvement in survival seen in recent years. ${ }^{7}$ HDT and ASCT are now seen as the standard of care for younger patients with MM and will form part of the treatment plan at some stage, be it initially or at the time of progression. ${ }^{8}$ Since the widespread adoption of ASCT in MM, different sequential treatment strategies have been explored, with each stage producing progressive tumor cytoreduction and increasing depth and rate of response. ${ }^{9,10}$

Many studies have been published that evaluate the use of stem cell transplantation (SCT) in MM. These have been comprehensively appraised in this review which covers the following areas: Induction and conditioning regimens (primarily in ASCT), different transplant protocols (namely ASCT, allogeneic SCT, tandem SCT), timing of SCT, consolidation and maintenance therapies post-SCT, prognostic factors and future directions of treatment. This paper will focus on first-line treatment in MM patients eligible for transplant; the treatment of refractory and relapsed disease post-SCT will not be covered in detail but will be touched upon in the context of the above areas. 


\section{Methodology of research}

Papers for this review were identified by searches of Medline, using keywords: STEM CELL TRANSPLANTATION and STEM CELL TRANSPLANT and AUTOLOGOUS TRANSPLANTATION and AUTOLOGOUS TRANSPLANT and MYELOMA. Limits added to this search were: i) human studies, ii) written in English, iii) all clinical trials, and iv) published between 1990 and the present day. The latter was considered suitable as this was the period in which the first stem cell transplantations for myeloma were reported (with the exception of a few case studies). Additional relevant papers identified were also referred to where appropriate.

\section{Induction regimens}

Different regimens trialed in ASCT have been reviewed by the IMWG. ${ }^{11}$ Important induction regimens which have demonstrated capability of inducing high CR, near CR (nCR) and very good partial response (VGPR) rates in phase III trials have been summarised in Table 1. A complicating factor in the interpretation of these trials is the lack of a standardized approach with respect to transplant allocation; patients had the option of undergoing upfront elective SCT or remaining on all or some of the drugs in induction, which introduces considerable bias when assessing the long-term effect of these regimens.

Better response to induction regimen before SCT, especially CR status, has been shown to improve survival outcomes post-transplantation in several studies. ${ }^{3,4}$ This emphasizes the importance of developing optimal induction regimens to maximize benefit from stem cell transplantation. CR rates have been enhanced by the widespread introduction of novel drugs, thalidomide, lenalidomide and bortezomib. ${ }^{19}$

\section{Thalidomide-based regimens}

\section{Thalidomide+dexamethasone versus dexamethasone}

The effectiveness of thalidomide as induction therapy has been identified in several phase II clinical trials..$^{20,21} \mathrm{~A}$ subsequent phase III trial, by The Eastern Cooperative Oncology Group (ECOG), confirmed this finding with an increase in post-induction response rate (RR), objective response defined as at least $50 \%$ reduction in monoclonal protein levels) when thalidomide+dexamethasone (TD) therapy was compared with dexamethasone alone. However, this occurred at the expense of increased toxicity and the study did not assess response or survival post-ASCT which is arguably more clinically relevant. ${ }^{12}$

\section{Thalidomide+dexamethasone versus vincristine+doxorubicin+} dexamethasone

The Bologna 2002/96 study, a retrospective analysis of 135 matchpairs of younger previously untreated MM patients who subsequently underwent tandem ASCT, compared TD with standard vincristine+doxorubicin+dexamethasone (VAD) therapy. A significant increase in response, namely at least VGPR, was found post-induction (30\% vs $15 \%$, $\mathrm{P}=0.003)$ and sustained post-first and second ASCT (60\% vs 30.5\%, $\mathrm{P}<0.001$ and $68 \%$ vs $49 \%, \mathrm{P}=0.001$, respectively). Progression-free survival (PFS) was greater in the TD group (at 4 years $51 \%$ vs $31 \%$, $\mathrm{P}=0.01$ ) and overall survival (OS) had a tendency to be prolonged (at 5 years $69 \%$ vs $53 \%, \mathrm{P}=0.07$ ), with novel agents administered postrelapse potentially obscuring the overall benefit. ${ }^{22}$

However, a prospective randomized controlled trial (RCT) comparing TD with VAD ( $\mathrm{n}=100$ vs 104$)$ in a similar patient population showed that despite a higher pre-transplant VGPR to TD (34.7\% vs $12.6 \%$, $\mathrm{P}=0.002$ ) both groups had similar VGPR post-transplantation. In the TD group, venous thromboembolism was significantly increased. ${ }^{23}$
Thalidomide in combination

TD along with doxorubicin and cyclophosphamide has been shown to produce better response rates when compared with VAD-based regimens. ${ }^{8}$ The multi-center phase III trial (MRC Myeloma IX) comparing thalidomide+cyclophosphamide+dexamethasone induction therapy with VAD in combination with cyclophosphamide revealed greater CR and comparable survival rates in the thalidomide group. ${ }^{13}$

The HOVON-50 trial showed that thalidomide in combination with adriamycin and dexamethasone (TAD) induction therapy was superior to vincristine+adriamycin+dexamethasone $\left(\mathrm{VAD}_{2}\right)$. PFS and eventfree survival (EFS) were increased in the thalidomide group post-ASCT but different maintenance therapies used in the two treatment groups may have influenced these results. OS rates were similar but the authors proposed that a longer follow-up period might elicit a significant difference in favor of thalidomide. ${ }^{14}$

\section{Bortezomib-based regimens}

\section{Bortezomib+dexamethasone}

A phase Ill trial [Intergroupe Francophone du Myelome (IFM 200501)] comparing the novel agent bortezomib+dexamethasone (VD) with the traditional VAD induction regimens found a consistently increased $\mathrm{CR} / \mathrm{nCR}$ pre- and post- $1^{\text {st }} / 2^{\text {nd }}$ transplants, including when the analysis was restricted to only those who ultimately received transplant and in those with high-risk disease. This translated into a similar OS rate but a trend towards an increase in PFS. Safety profiles were comparable, with reduced toxicity-associated deaths in the bortezomib group but increased rates of peripheral neuropathy. In addition, fewer patients in the bortezomib group required a $2^{\text {nd }}$ ASCT ( $38.6 \%$ vs $56 \%$, $\mathrm{P}=0.001) \cdot{ }^{15}$

\section{Bortezomib in combination}

Bortezomib in combination with other cytotoxic drugs has shown promising benefits. ${ }^{8}$

A retrospective analysis compared two multi-drug induction therapies: total therapy 3 (TT3) which included bortezomib and total therapy 2 (TT2) which did not ( $\mathrm{n}=303$ vs 668 ). This showed a significantly longer duration of CR (albeit the same initial response), increased EFS and a trend towards increased OS in the total therapy groups. This was in spite of a shorter follow up and significantly different characteristics of the TT3 group, namely older population, greater prevalence of raised beta-2-microglobulin $(\beta 2 \mathrm{~m})$ and higher stage disease. ${ }^{24}$

A meta-analysis of 4 phase III randomized trials (total 2086 patients) comparing bortezomib-containing combination induction regimens (BCIR) and non-BCIR showed favorable outcomes in the bortezomib group at post-induction as well as post-transplant. PFS and OS were also superior in the bortezomib group. However, adverse events, namely peripheral neuropathy and herpes zoster infections, were higher in BCIR with relative risks of $4.69(\mathrm{P}=0.000)$ and $2.197(\mathrm{P}=0.001)$, respectively. ${ }^{25}$

\section{Lenalidomide}

Lenalidomide, a drug relative of thalidomide, could potentially offer improved benefit with a much lower incidence of peripheral neuropathy $(\mathrm{PN}){ }^{8}$ Early trials assessing the potential use of lenalidomide in induction therapies have been carried out but have not yet reached large-scale phase III trials.

\section{Bortezomib+thalidomide}

In light of the confirmed benefits of both TD and bortezomib, several studies have explored the use of these in a triple therapy regimen (VTD). One multicenter trial by the Italian Myeloma Network (GIMEMA) compared VTD with TD alone and found a significant 

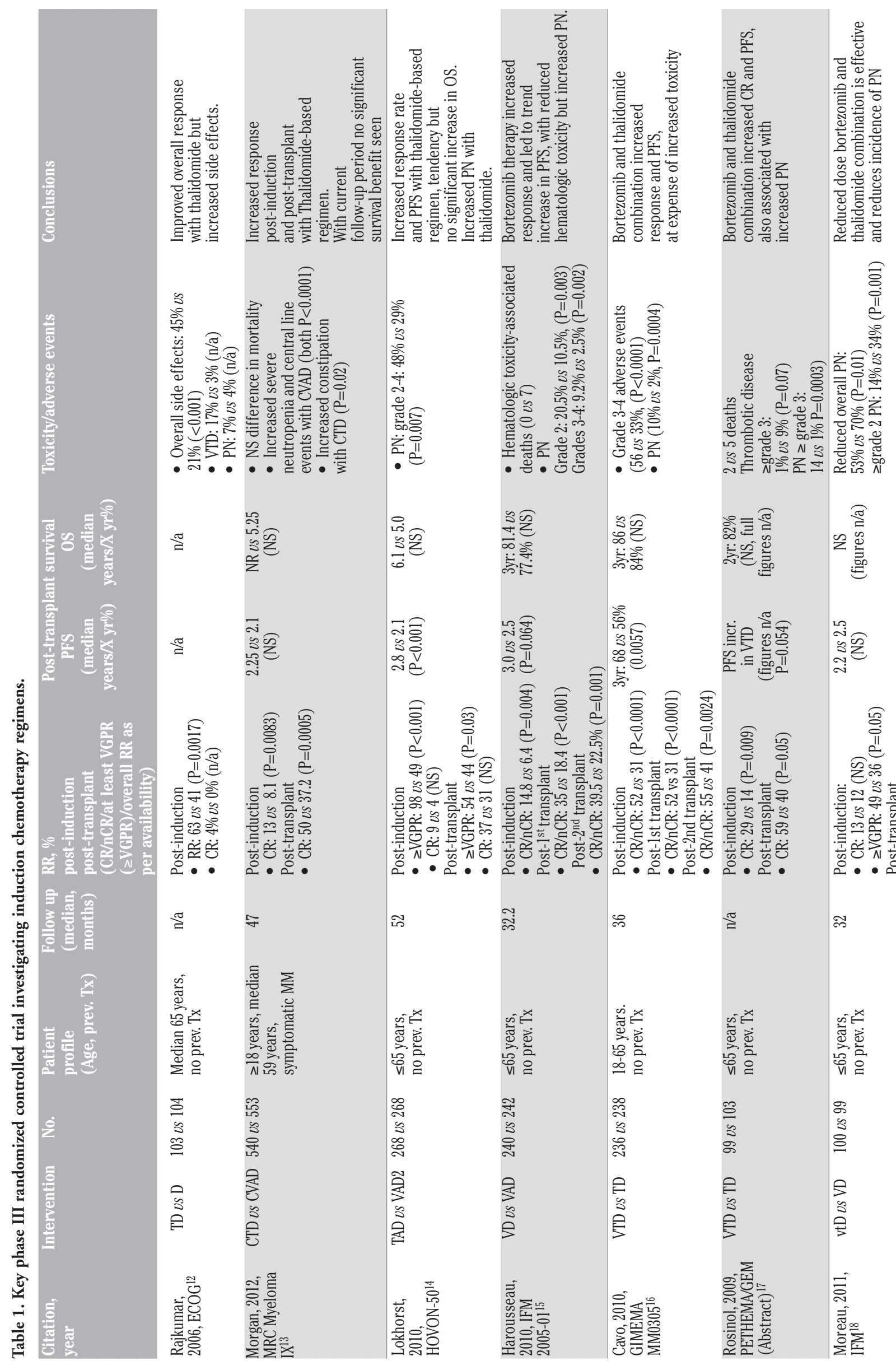

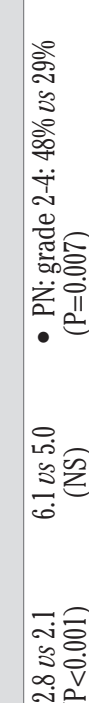

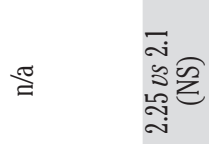
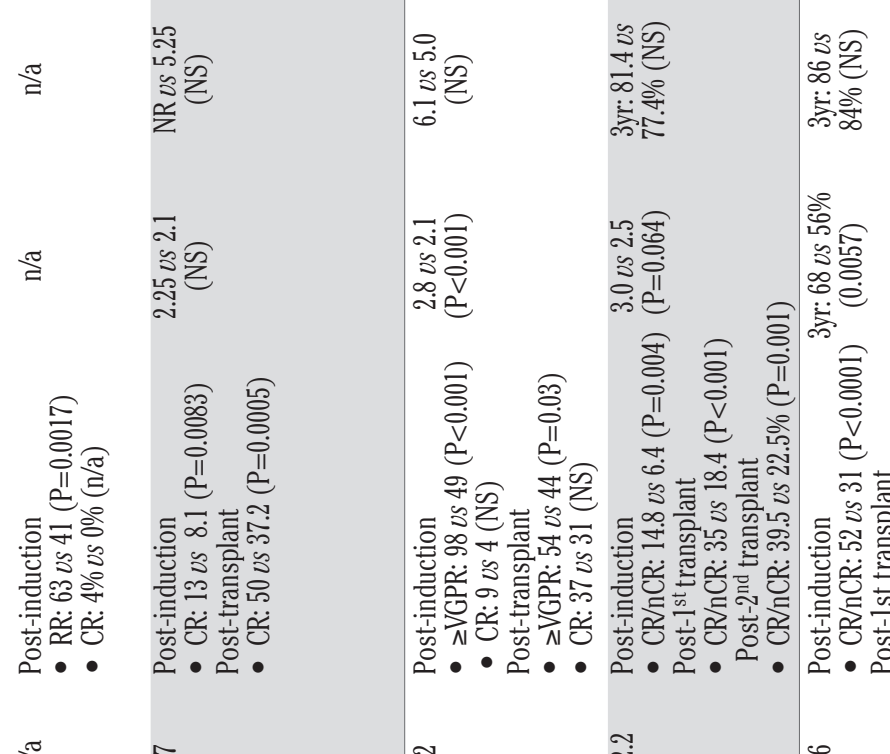

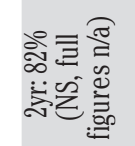
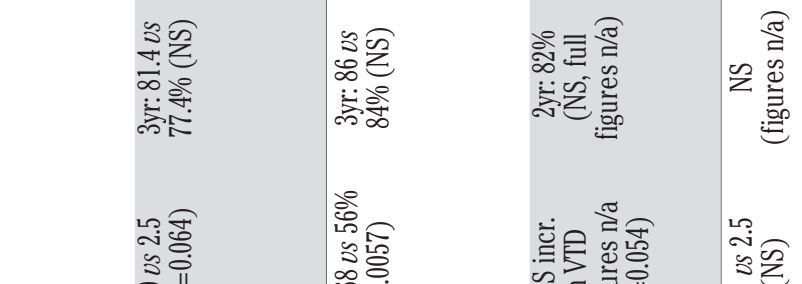

政

$\stackrel{\Im}{\exists}$

กิ

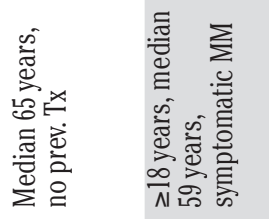

落

学管

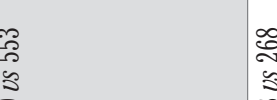

○

คั

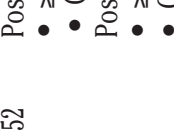

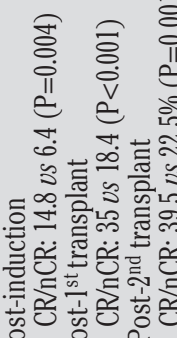

है

言

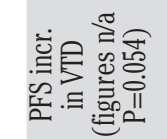
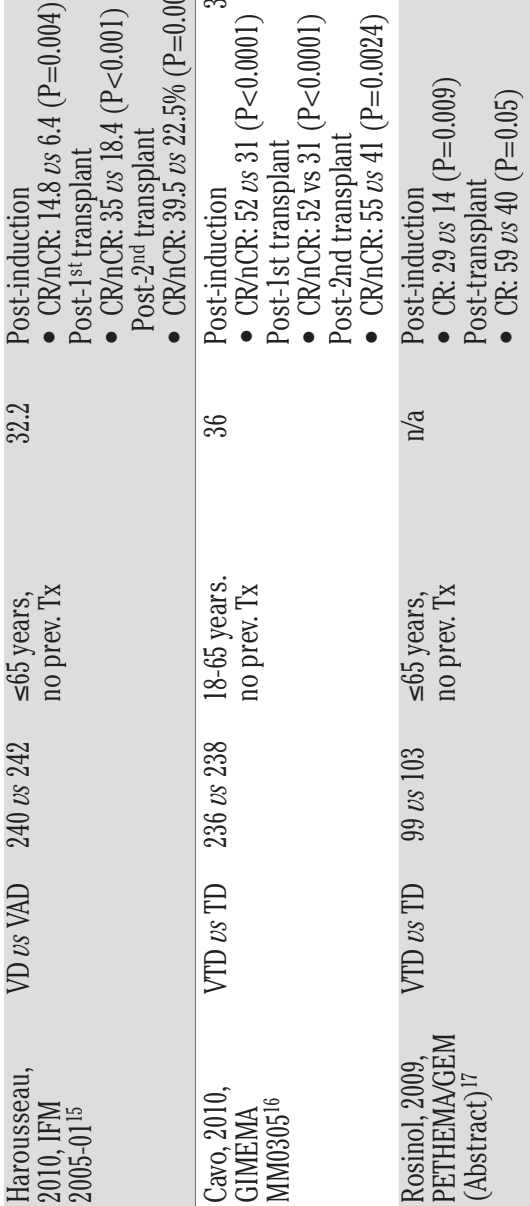

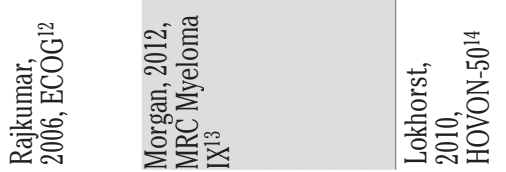
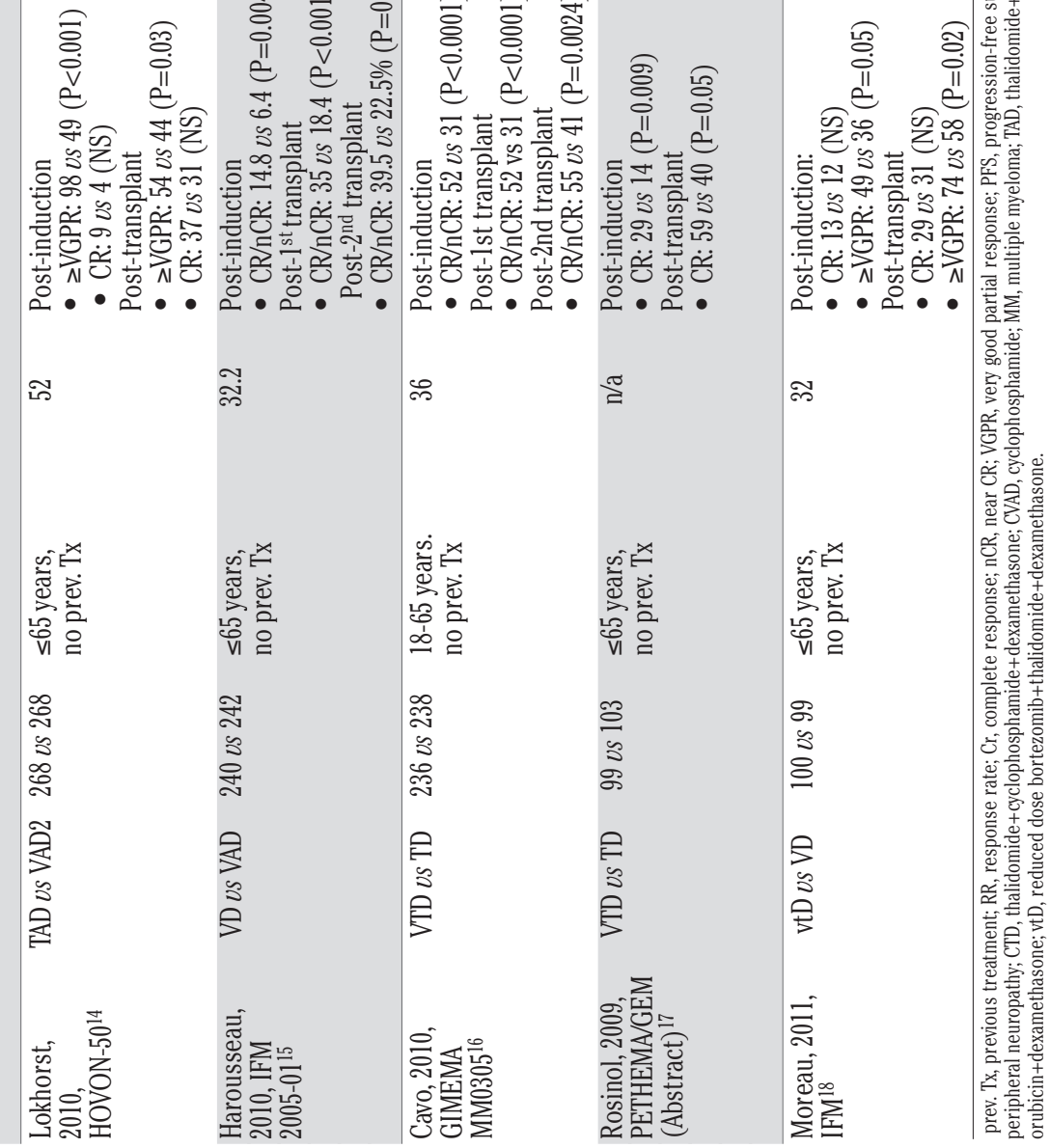
increase in $\mathrm{CR} / \mathrm{nCR}$ post-induction in the bortezomib group,${ }^{16}$ findings which have been supported by work by the Spanish Myeloma Group (PETHEMA/GEM). ${ }^{17}$ However, in both trials, incidence of PN was increased in the triple therapy group.

A recent IFM-led randomized trial comparing VD with reduced dose bortezomib, thalidomide and dexamethasone (vtD) showed an improvement in at least VGPR and reduced incidence of PN in the triple therapy group. However, with increased consolidation treatment in the VD group post-ASCT, conclusions regarding OS cannot be drawn. ${ }^{8}$

\section{Bortezomib+lenalidomide}

Lenalidomide in combination with VD therapy has been investigated in a small phase I/II trial, proving effective with favorable tolerability, warranting further investigation. ${ }^{26}$ Quadruple therapy has been explored but results are conflicting regarding the potential benefit over triple therapy. One phase I/II trial, assessing the combination of lenalidomide, bortezomib, pegylated doxorubicin and dexamethasone, suggested that a $4^{\text {th }}$ agent could augment the responses seen. ${ }^{27}$ However, the phase II EVOLUTION trial found that triple combinations of either lenalidomide or cyclophosphamide with bortezomib and dexamethasone and the 4-drug regimen produced comparable responses, and greater toxicity was seen with the latter. ${ }^{28}$ The authors suggest that triple therapy is the most promising and use of cyclophosphamide instead of lenalidomide has potential cost saving benefits.

\section{Induction regimens: conclusions}

Based on current evidence, for transplant-eligible MM patients, a bortezomib-based induction is associated with improved disease control after transplantation and should be considered the standard of care in the absence of a randomized trial comparing this with lenalidomide. For the moment, VD forms the backbone of induction therapy in myeloma. Novel agent combination therapy may feature more prominently in the future but further investigation is needed.

\section{Conditioning regimens}

The first stem-cell transplantations with HDT used total body-irradiation (TBI, 840cGy) and then melphalan $140 \mathrm{mg} / \mathrm{m}^{2}$ (MEL140). ${ }^{29}$ Whilst effective, this therapy proved toxic. The use of triple alkylator therapy, namely thiotepa, reduced-dose busulfan and cyclophosphamide, was explored as an alternative; a good response was seen but treatment-related mortality (TRM, 13\%) was similar to MEL140+TBI treatment. ${ }^{30}$ The IFM 9502 randomized trial compared MEL200 with MEL140+TBI ( $\mathrm{n}=142$ vs 140) in younger, newly diagnosed MM patients undergoing ASCT. MEL200 was less toxic and at least as effective, with suggestions of increased response and survival benefits (45-month OS: $64 \%$ vs $46 \%$, $\mathbf{P}=0.05$ ). There were shorter periods of hospitalization, neutropenia and thrombocytopenia, and lower rates of severe mucositis in the MEL200 group. ${ }^{31}$ Typically, a $20-30 \%$ CR is seen with this high-dose melphalan therapy (HDM). Currently, HDM is accepted as the standard preparative regimen for ASCT, as no other treatment has yet offered better outcomes with acceptable toxicity levels. However, relapse in MM is almost inevitable prompting further trials of different combination therapies. So far, results are inconclusive, particularly as in many exploratory retrospective studies prior induction therapies differ between groups.

\section{Bortezomib+high-dose melphalan therapy}

Bortezomib (Bor) in combination with MEL200 was compared with
MEL200 alone ( $\mathrm{n}=46$ vs 115$)$ in a retrospective study using matched controls from a previous study by the same IFM group. They found a significantly increased CR rate with Bor+HDM $(35 \%$ vs $11 \%, \mathrm{P}=0.001)$ with no adverse toxicity, and whilst survival analyses were not compared, estimated 2-year PFS and OS were $75 \%$ and $96 \%$, respectively. ${ }^{32}$ Therefore, Bor+HDM is a promising regimen but randomized trials are required to confirm any potential benefits over melphalan alone. Of note, post-ASCT CR rate (11\%) in the historical control group was inferior to that normally expected with melphalan alone. This may have contributed to the apparent superiority of the Bor+HDM regimen, especially as there was not much difference between the CR rate seen with this treatment (34\%) and that normally seen with HDM alone.

\section{Busulphan+high-dose melphalan therapy}

A small study of 30 patients comparing BUMEL (busulfan $16 \mathrm{mg} / \mathrm{kg}+$ melphalan $100 \mathrm{mg} / \mathrm{m}^{2}$ ) with MEL200 alone found overall response was greater in the BUMEL group ( $85 \%$ vs $75 \%, \mathrm{P}<0.05)$ as was median PFS (10.5 vs 9 years, $\mathrm{P}=0.05$ ) but $\mathrm{OS}$ and toxicity profiles were similar. ${ }^{33}$ The Spanish PETHEMA/GEM2000 trial compared BUMEL (busulfan 12 $\mathrm{mg} / \mathrm{kg}+$ melphalan $140 \mathrm{mg} / \mathrm{m}^{2}$ ) with MEL200 ( $\mathrm{n}=225$ vs 542 ); this was an open switch study due to the high frequency of veno-occlusive disease (VOD) seen with BUMEL. An increase in overall TRM was seen ( $8.4 \%$ vs $3.5 \%, \mathrm{P}=0.002$ ) in the BUMEL group largely due to VOD. Single or tandem transplants were offered depending on whether or not $\mathrm{CR} / \mathrm{nCR}$ was achieved post-1st transplant; those in the BUMEL group had a higher rate of tandem transplantation ( $54 \%$ vs $35 \%, \mathrm{P}=0.001)$. PFS was increased with BUMEL therapy (median 3.4 vs 2.5 years, $\mathrm{P}=0.009$ ) which persisted when tandem transplants were excluded. ${ }^{34}$

\section{Carmustine+high-dose melphalan therapy}

Recently, carmustine $\left(500 \mathrm{mg} / \mathrm{m}^{2}\right)$ was trialed with MEL200 (BCNU/HDM) in a retrospective comparative study with HDM alone (104 vs 103 patients, respectively). This found an increased EFS in the $\mathrm{BCNU} / \mathrm{HDM}$ group (3.5 vs 1.8 years, respectively, $\mathrm{P}=0.013$ ) with $17 \%$ of patients event-free without any further treatment at seven years. There was also a trend for prolonged OS in this group. ${ }^{35}$

Carmustine $\left(300 \mathrm{mg} / \mathrm{m}^{2}\right)$ has also been trialed in combination with etoposide, cytarabine (both $\left.100 \mathrm{mg} / \mathrm{m}^{2}\right)$ and melphalan $\left(140 \mathrm{mg} / \mathrm{m}^{2}\right)$ in the BEAM regimen and compared with melphalan alone (140 or 200 $\mathrm{mg} / \mathrm{m}^{2}$ ) in a retrospective study (76 vs 103 patients, respectively). ${ }^{36}$ This study also found survival benefits with combination therapy with a reduction in treatment failure $(37 \%, \mathrm{P}=0.01)$ and death $(31 \%$, $\mathrm{P}=0.009$ ) in the BEAM group. In both of these studies, follow-up periods were much shorter in the HDM alone group which may have affected the results seen. However, TRM rates were similar and it would appear that high-dose combination regimens warrant further investigation in prospective randomized trials.

\section{Transplantation protocols}

\section{Type of transplantation}

\section{Single versus double autologous hematopoietic stem cell trans-} plantation

Double ASCT has improved survival markers when compared with single ASCT in several phase III clinical trials (Table 2). The Bologna 96 study, a large RCT of 321 patients, found a significant increase in $\mathrm{CR} / \mathrm{nCR}$, EFS and relapse-free survival (RFS) with upfront tandem versus single ASCT. The benefit was most notable in the subpopulation who failed to achieve nCR post- $1^{\text {st }}$ ASCT. ${ }^{37}$ In the IFM 96 randomized study, a trend towards an increase in response was seen with tandem 


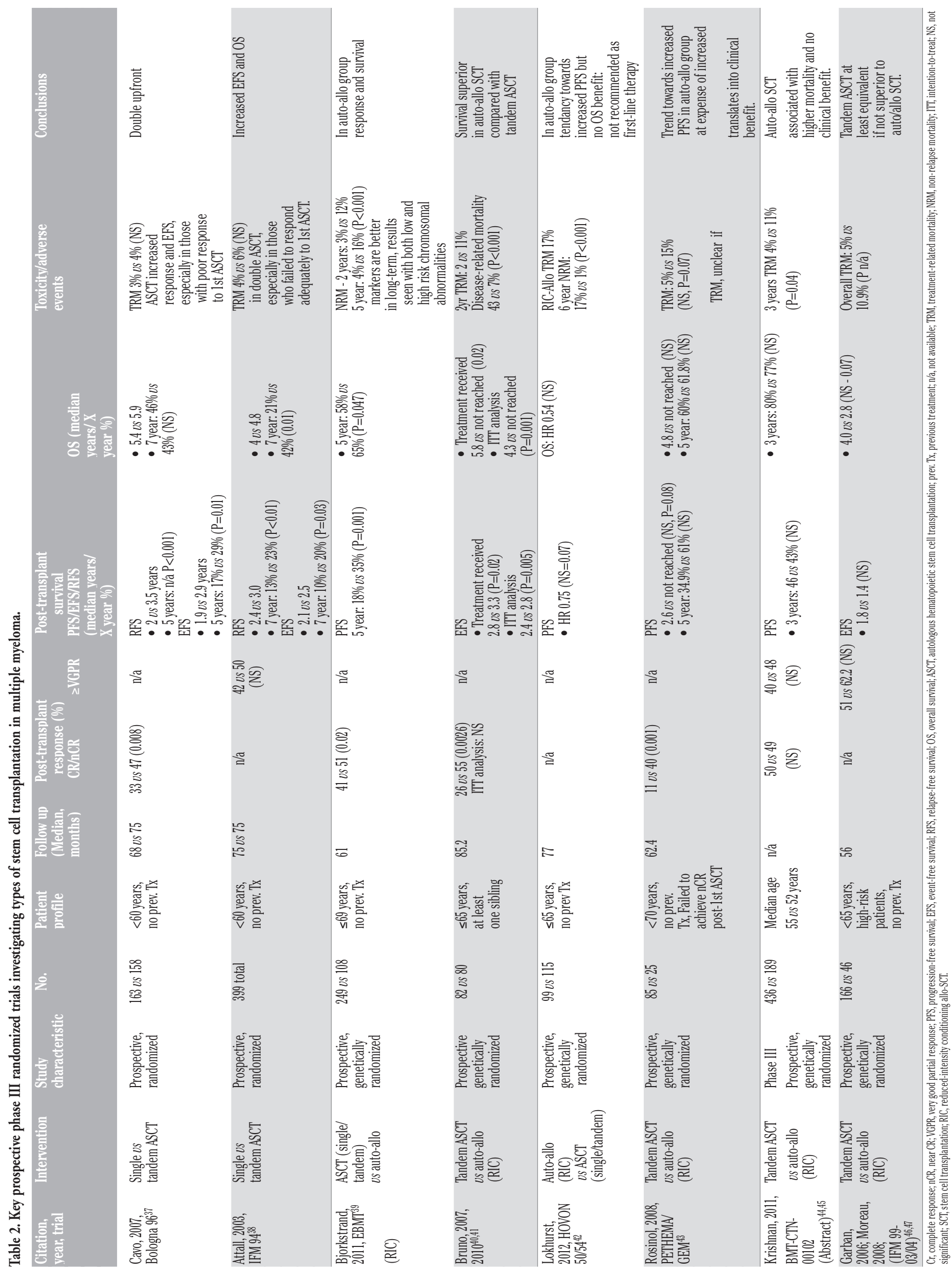


ASCT but did not reach significance in intention-to-treat analysis. There was, however, a significant increase in EFS, RFS and estimated OS. The survival benefit was enhanced in the subgroup of patients who failed to demonstrate a good response three months post 1st-transplant, when 7-year OS increased from 11\% to $43 \%(\mathrm{P}<0.001)$. On the contrary, in those with at least VGPR after $1^{\text {st }} \mathrm{ASCT}$, there was no significant increase in response post- $2^{\text {nd }}$ ASCT. This study suggested the importance of a significant follow-up period, in this case a minimum of five years, in order to see the survival benefits of tandem ASCT. ${ }^{38}$ Another prospective study, albeit non-randomized, supported these findings. ${ }^{48}$ A multivariate analysis incorporating several trials discussed above has supported the benefit of tandem over single transplant and standard chemotherapy $(\mathrm{HR}=0.61, \mathrm{P}<0.001) .{ }^{49}$ Whilst consistently improved response rates are reported with double transplants, it is not clear how much of this is attributable to the transplant per se or due to different regimens and absolute doses of chemotherapy administered in the induction and conditioning processes.

Triple autologous hematopoietic stem cell transplantation: small feasibility trials

Small trials have investigated the possibility of triple ASCT, with low dose melphalan $\left(100 \mathrm{mg} / \mathrm{m}^{2}\right)$ in those patients with advanced disease and poor performance status. These aimed to address the feasibility of this new treatment option in this large subgroup of patients who are unfit for high-dose transplant. The protocol was tolerated with promising results, albeit with small numbers, but larger studies are required before firm conclusions can be drawn. ${ }^{50,51}$

\section{Role of allogeneic stem cell transplantation}

The role of allogeneic SCT (allo-SCT) in MM is still a subject for debate and needs further exploration in clinical trials as TRM and graftversus-host disease (GvHD) remain unacceptably high even in the nonmyeloablative/reduced-intensity conditioning allo-SCT (RIC allo-SCT) setting. The IMWG has recently reviewed the role of allo-SCT in MM and studies comparing ASCT with RIC allo-SCT were summarized in that review. ${ }^{52}$

Several studies have not found any significant benefit of allo-SCT over ASCT. ${ }^{53,54}$ A large retrospective case-matched study by the European Group for Blood and Marrow Transplantation (EBMT) incorporating 189 patient pairs with comparable characteristics (except for median age, lower in the allogeneic group) identified a lower combined relapse/progression rate with allo-SCT $(\mathrm{P}=0.04)$ but this did not outweigh the accompanying increase in TRM (3 years: $41 \%$ vs $13 \%$, $\mathrm{P}=0.0001$ ) and reduction in $\mathrm{OS}$ (median 1.5 vs 2.8 years, $\mathrm{P}=0.001$ ). ${ }^{54}$

Alternative regimens of reduced-intensity conditioning have now been widely adopted to improve TRM. A comparative study of RIC versus myeloablative allo-SCT by the EBMT, combining data from 103 centers, concluded that the reduction in non-relapse mortality and acute GvHD seen with RIC allo-SCT were not offset by the increased relapse rate. However, interestingly, there was marked heterogeneity between patient groups and RIC regimens, and increased use of T-cell depleting agents, particularly alemtuzumab, in the RIC allo-SCT group, associated with higher relapse rates. ${ }^{55}$ At present, allo-SCT, including RIC regimens, as part of front-line therapy should be considered only in the context of clinical trials. Younger high-risk MM patients or patients who have suboptimal response to induction therapy can be considered for this approach if a fully matched donor is available, otherwise this should be used as a salvage therapy.

\section{Autologous hematopoietic stem cell transplantation versus auto-allo tandem transplants}

Several phase III trials (Table 2) discussed below have compared single/tandem ASCT with auto-allo tandem SCT. Results are conflicting due, at least in part, to differences in patients' characteristics and chemotherapy regimens. Studies were genetically randomized depending on the availability of human keukoyte antigen (HLA)-matched donors and RIC allo-SCT was used.

Both an EBMT and an Italian multicenter trial have favored auto-allo SCT over ASCT in terms of response, PFS and OS. ${ }^{39-41}$ In the EBMT trial, the benefits in the auto-allo group were only seen two years post-treatment, emphasizing the importance of long follow-up periods. In this study, less than half of the control group received a tandem transplant; this may have influenced the results but similar results were seen overall and in the tandem group sub-analysis. ${ }^{39}$

Similarly in the Italian study, a large number of patients were unable to receive both allocated transplants. Thus the difference in CR was not significant when groups were compared on an intention-to-treat (ITT) basis. ${ }^{40,41}$ However, survival markers were still improved and the presence of an HLA-identical sibling was associated with improved outcome regardless of the actual treatment received in both this study and the HOVON trial. ${ }^{42}$ In the HOVON 50/54 and PETHEMA/GEM trials, results were inconclusive, with a tendency towards increased PFS in the autoallo group at the expense of increased TRM. ${ }^{42,43}$ Of note, in the HOVON trial the majority of the control group received only one ASCT.

A further multicenter study (BMT-CTN 0102) of 625 standard risk myeloma patients found no significant differences in survival between groups but an increase in TRM in the auto-allo group. ${ }^{44,45} \mathrm{~A}$ secondary analysis of a cohort of 85 high-risk myeloma patients found a tendency towards reduced incidence of relapse/progression in the auto-allo group at three years ( $33 \%$ vs $53 \%, \mathrm{P}=0.09)$ warranting further investigation. ${ }^{56}$ An IFM trial focusing on high-risk patients (i.e. raised $2 \mathrm{~m}$ and chromosome 13 abnormalities) found that tandem ASCT was at least equivalent to auto-allo SCT, with a trend towards an increase in OS with tandem ASCT. 46,47

\section{Syngeneic transplant}

Whilst this option is limited to a small subpopulation, results have been promising. A retrospective case-matched control analysis of 80 syngeneic transplants identified a lower relapse/progression rate in the syngeneic group in comparison to ASCT $(\mathrm{RR}=0.49, \mathrm{P}=0.011)$ although $\mathrm{OS}$ was similar. There was a trend towards an increase in TRM and only 2 cases of mild GvHD. ${ }^{57}$ A smaller case-matched comparative EBMT study found improved PFS and a tendency towards increased OS in syngeneic transplant recipients compared with ASCT and allo-SCT, albeit with a similar CR. ${ }^{58}$

\section{Timing of $1^{\text {st }}$ transplant}

One ongoing clinical question is whether to use stem cell transplant as an initial intensifying regimen upfront or as a reserve strategy for those who relapse. This will become increasingly relevant as newer induction therapies produce better CR/VGPR rates: will the additional benefits of SCT outweigh the risks of associated mortality and morbidity? One multicenter randomized trial investigated optimal timing of ASCT in young myeloma patients with an early group receiving transplant upfront $(\mathrm{n}=91)$ and a later group receiving CCT +/- rescue SCT $(\mathrm{n}=94)$ if primary resistance or relapse occurred. OS was similar, exceeding five years in both groups $(\mathrm{P}=0.92)$, but $\mathrm{EFS}$ was unsurprisingly longer in the upfront group. (It was acknowledged that a direct comparison between groups was perhaps not valid as the CCT group ultimately received HDT post-relapse.) Upfront SCT may be preferred due to the shorter period of chemotherapy. ${ }^{59}$

A post hoc retrospective analysis of an ECOG study compared upfront ASCT with continued lenalidomide and dexamethasone. All patients were initially treated with four cycles of the above chemotherapy. There was an apparent OS benefit of upfront SCT in all age groups (3-year: $94 \%$ vs $78 \%$ in those $<65$ years) although direct comparison was limit- 
ed as this trial was not randomized. ${ }^{60}$

A randomized phase III study of 402 younger, newly diagnosed patients also identified a potential survival advantage of upfront ASCT over chemotherapy alone (melphalan+prednisolone+lenalidomide). However the improvement in 2-year PFS $(73 \%$ vs $54 \%, \mathrm{P}<0.001)$ did not convert into OS benefit and greater toxicity was seen in the ASCT group. ${ }^{61}$

\section{Timing of $2^{\text {nd }}$ transplant: reserve as salvage therapy?}

Whilst the treatment of relapse post-SCT is not the focus of this review, it is worth mentioning that there is scope for single transplantation with a subsequent transplantation post-relapse, rather than tandem transplantation upfront.

In one study, 130 patients underwent HDT and ASCT +/- second ASCT in the case of relapse/progression; 107 (82\%) patients completed the 1st stage and in the 70 patients who relapsed or progressed, 26 underwent a $2^{\text {nd }}$ transplant. Median OS and EFS were 3.2 and 1.2 years, respectively, after $2^{\text {nd }}$ transplant; notably less than the studies above with upfront tandem transplants. Interestingly, in $10 \%$ of patients it was more than one year until the best response was seen post-1 $1^{\text {st }}$ transplant, suggesting that at least part of the response seen with tandem ASCT may be due to delayed effects of the $1^{\text {st }}$ ASCT. ${ }^{62}$

\section{Consolidation regimens}

Residual disease is almost always present after transplantation in MM patients and is responsible for relapse. However, the role of minimal residual disease (MRD) testing has not been widely adopted in MM. Until recently, achieving a CR, as defined by IMWG criteria was rare in patients with $\mathrm{MM} .^{63}$

A multicenter Italian study investigated the effect of a consolidation regimen, which included VTD, on MRD by qualitative and real-time quantitative polymerase chain reaction (RQ-PCR). Patients with MM responding to auto-SCT, achieving at least very good partial response, with an available molecular marker based on the immunoglobulin heavy-chain rearrangement, received VTD consolidation. Thirty-nine patients were enrolled, with 31 receiving all four VTD courses. Immunofixation CR increased from 15\% after ASCT to 49\% after VTD consolidation. Molecular remissions (MRs) were 3\% after ASCT and $18 \%$ after VTD. Median time to maximum response was 3.5 months. № patient in MR has relapsed at a median follow up of 42 months. ${ }^{64}$ In a randomized phase III study, superior CR/nCR rates and extended PFS were demonstrated with VTD versus TD as induction therapy before, and consolidation after, double ASCT for newly diagnosed myeloma patients. Although there was no significant difference in $\mathrm{CR} / \mathrm{nCR}$ rates before starting the consolidation in the VTD (63.1\%) and TD arms (54.7\%), after consolidation $\mathrm{CR} / \mathrm{nCR}$ (73.1\% vs $60.9 \%)$ rates were significantly higher for VTD-treated patients; this was accompanied by an increase in 3-year PFS (60\% vs 48\%). Grade 2-3 peripheral neuropathy ( $8.1 \%$ vs $2.4 \%$ ) was more frequent with VTD consolidation. ${ }^{65}$ The superior efficacy of VTD versus TD as induction was retained despite readministration as consolidation therapy after double ASCT.

\section{Maintenance regimens}

The consensus definition of maintenance therapy in myeloma is any treatment administered after the completion of induction therapy in patients whose disease is either responsive or non-progressive at that time, with the goal of prolonging survival. In an attempt to delay relapse, which is inevitable in a large proportion of patients, several maintenance strategies have been investigated. These have been recently summarized in an IMWG review but none of the current drugs have yet been approved.$^{66}$ With no widely adopted standard treatment, choice of maintenance treatment remains a personal one based on the individual. The immunomodulators thalidomide and lenalidomide have been the most frequently studied maintenance drugs, given their established anti-myeloma efficacy and ease of oral administration. Relevant phase III trials are summarized in Table 3.

\section{Thalidomide}

Benefits have been demonstrated with thalidomide in several RCT. ${ }^{7,68}$ Another study by the MRC-UK (Myeloma IX trial) investigated the role of maintenance thalidomide compared with no maintenance therapy in an open label, multicenter RCT, with particular consideration given to cytogenetic profiles (using FISH). PFS was increased with thalidomide therapy but there was no overall significant difference in OS which was in fact worse in those with poor cytogenetics. Poorer median OS post-progression in the thalidomide maintenance group was only seen in those (41\%) who received thalidomide salvage therapy, which may be related to the emergence of drug-resistant subclones. The toxicity profile of thalidomide caused a high dropout rate with median duration of treatment of only seven months. ${ }^{69}$

The MRC group also performed a meta-analysis of five RCT trials (including the three above) incorporating 2456 patients, focusing on only $\mathrm{OS}$, and found an increase with thalidomide maintenance therapy $(\mathrm{P}=0.047)$. The heterogeneity between studies, largely due to use of thalidomide post-relapse, was removed by modeling the results with effective salvage therapy and also increased the apparent impact of thalidomide on OS $(\mathrm{P}<0001)$; the authors suggest that better salvage therapies may improve potential OS benefit of thalidomide maintenance therapy.$^{69}$ Another meta-analysis by the IMWG found an increase in both PFS (HR 0.64, P<0.000) and OS (HR 0.84, P<0.001) ${ }^{66} \mathrm{~A}$ further large meta-analysis of phase III trials of thalidomide maintenance therapy, incorporating 3194 patients confirmed superiority of this treatment in terms of both PFS (HR 0.62, $\mathrm{P}=0.000$ ) and 3-year OS (HR 0.8, $\mathrm{P}=0.001)$. Significant toxicity was seen in the thalidomide maintenance group, namely peripheral neuropathy and thromboembolic events which were particularly pronounced with thalidomide and steroid in combination. ${ }^{75}$

\section{Lenalidomide}

The peripheral neuropathy seen with thalidomide may be avoided with a related immunomodulator and antiangiogenic drug, lenalidomide. A placebo-controlled IFM-led RCT (2005-02) investigated the efficacy of lenalidomide maintenance therapy after SCT and found that it was well tolerated and increased PFS but not $0 \mathrm{~S}^{70} \mathrm{In}$ a further doubleblind RCT of 460 patients (CALGB 100104 trial with 231 vs 229 on lenalidomide and placebo, respectively) lenalidomide also improved survival markers. However, lenalidomide also, unsurprisingly, caused greater toxicity than placebo, albeit to an apparently lesser extent than thalidomide. ${ }^{71,72}$ Additionally, there are long-term side effects to consider, namely increased incidence of subsequent malignancies with lenalidomide, seen in both studies.

\section{Bortezomib}

The HOVON-65/GMMG-HD4 trial investigated the role of bortezomib maintenance. Arm A received standard VAD induction therapy and lowdose thalidomide $50 \mathrm{mg} /$ day post-ASCT and Arm B was given bortezomib-containing bortezomib+doxorubicin+dexamethasone induction therapy and bortezomib maintenance $\left(1.3 \mathrm{mg} / \mathrm{m}^{2}\right.$ every 2 weeks). Survival markers were significantly better in Arm B containing bortezomib. ${ }^{73}$ 


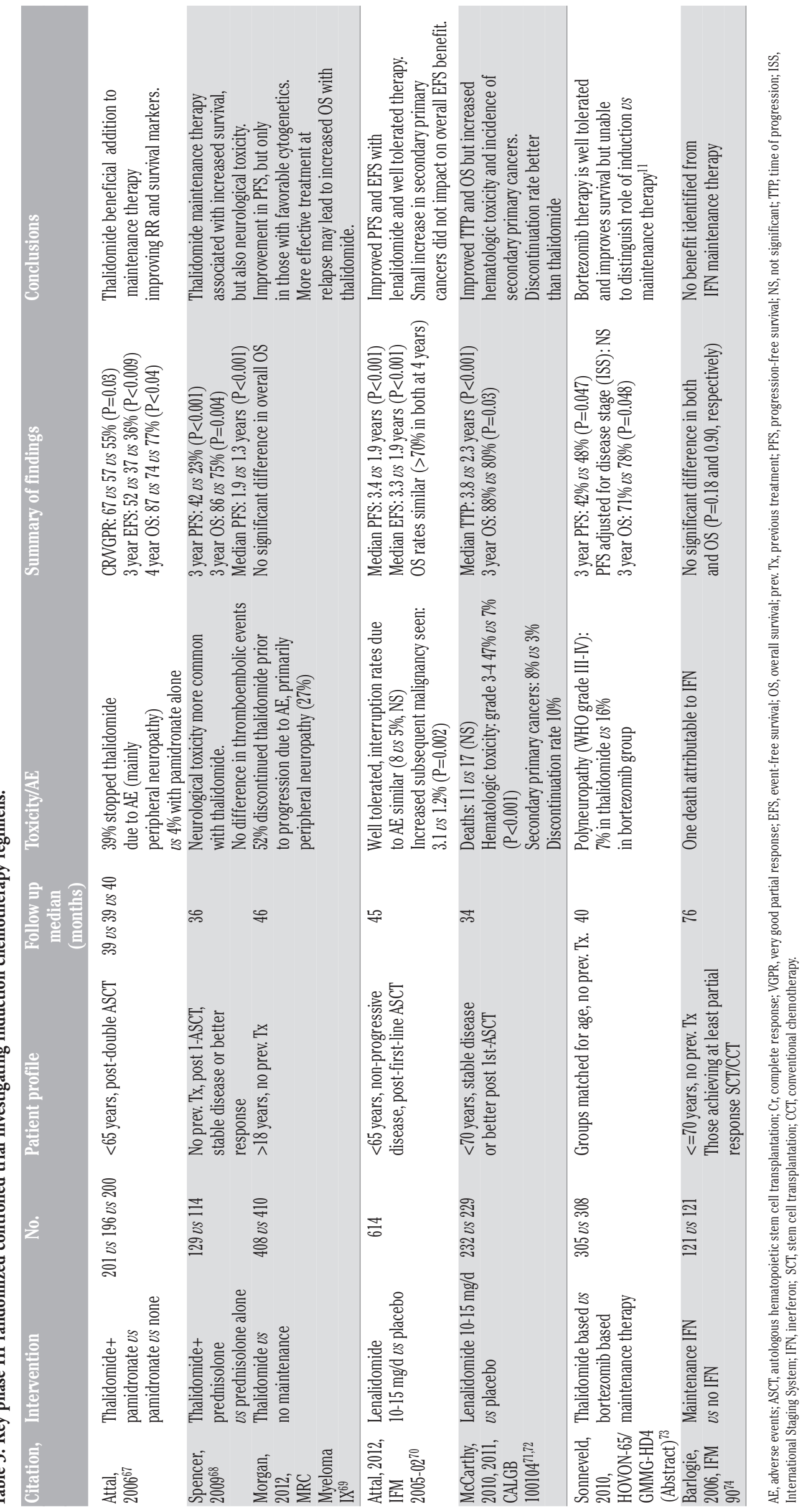




\section{Interferon}

Interferon-alpha has been investigated in several RCT with conflicting results. One meta-analysis of 30 RCTs (13 in maintenance therapy with a total of 1615 patients) found a prolongation of relapse-free and overall survival with interferon maintenance: $4.4(\mathrm{P}<0.01)$ and 7.0 $(\mathrm{P}<0.01)$ months respectively. ${ }^{76}$ In the IFM 90 trial, comparing HDT and standard-dose therapy in myeloma patients, interferon maintenance was randomly assigned to those achieving more than $75 \%$ response; no significant benefit of interferon was seen. ${ }^{74}$

\section{Prognostic factors in transplantation}

In addition to response to induction therapy, there are numerous other factors which may help predict outcome of SCT.

\section{Previous treatments}

Administration of only one treatment regimen prior to SCT is associated with better survival, ${ }^{77}$ whereas previous radiotherapy and more than two chemotherapy regimens is linked to poorer outcomes. ${ }^{78}$ Previous ASCT is predictive of longer PFS and OS in RIC allo-SCT. ${ }^{79}$

\section{Pre-transplant molecular, cytogenetic and biochemical factors}

Overexpression of cyclin-D1 is associated with longer remission periods (41 vs 26 months, $\mathrm{P}=0.02$ ) ${ }^{80}$ Higher $\beta 2 \mathrm{~m}$ levels at diagnosis $(>3.5 \mathrm{mg} / \mathrm{mL}$ ) are predictive of shorter survival in tandem auto-allo SCT, ${ }^{81}$ whilst lower levels predict longer PFS and OS post-SCT.77,78 Increased expression of interleukin-6 receptor anticipates poorer prognosis post-ASCT. ${ }^{82}$ Higher plasma cell labeling index is an accepted poor prognostic indicator in myeloma. ${ }^{83}$ Abnormalities in chromosomes $11 \mathrm{q}$ and 13 and presence of chromosome 13 deletion and translocations $\mathrm{t}(4 ; 14)$ and $\mathrm{t}(14 ; 16)$ predict adverse outcomes post-SCT. ${ }^{4,84-86}$

\section{Timing of transplant}

Prolonged time (>10-12 months) between diagnosis and receiving SCT anticipates poorer survival outcomes in both auto-allo and ASCT transplant protocols. . $^{81,87,88}$

\section{Post-transplant molecular markers}

Examination of bone marrow plasma cells (BMPC) may offer a good predictor for progressive disease in those achieving complete remission post-SCT: 35 patients initially in serological CR were followed-up for a median 7.3 years post-ASCT with microscopic evaluation, identifying presence of more than $1.5 \% \mathrm{BMPC}$ as a risk factor for progressive disease $(\mathrm{P}=0.016){ }^{89}$

MRD was investigated in a study of 295 patients using multiparameter flow cytometry: 100 days post-ASCT MRD negative patients had significantly longer median PFS (71 vs 37 months, $\mathrm{P}<0.001$ ) and OS (not reached $v s 89$ months, $\mathrm{P}=0.002) .{ }^{90}$

\section{Disease stage according to staging system}

The Southwest Oncology Group and the International Staging System are the most reliable predictors of PFS and OS, better still if used at time of diagnosis rather than time of transplant. ${ }^{91}$

\section{Patients' characteristics including performance status and age}

Lower Karnofsky performance status score $(<90 \%)$ is a poor prognos- tic factor. ${ }^{81}$ A study of the EMBT Registry assessed prognostic factors in ASCT, associating male sex and age under 45 years with better survival. ${ }^{77}$ Other studies have questioned this association between age and transplant outcome, concluding that other factors have a more prominent influence and age alone should not be an exclusion criterion. ${ }^{92}$

\section{Role of transplantation in advanced disease and elderly patients}

The majority of patients deemed suitable for transplantation, especially allogeneic, are younger. Most of the above studies are in newly diagnosed young patients with limited information on what actually accounts for a large number of patients encountered in clinical practice: elderly, heavily pre-treated, with multiple co-morbidities. Some studies have investigated alternative approaches to address this, such as triple ASCT. ${ }^{50,51}$

Some small studies have reported that SCT is a safe option for selected elderly patients. A retrospective case-matched analysis of 71 pairs of elderly patients found that MEL100 with ASCT was superior to melphalan and prednisolone in terms of CR, EFS and OS. ${ }^{93}$ Small comparative studies of high-dose melphalan and ASCT in selected elderly and younger populations found that this protocol was safe and effective. ${ }^{94,95}$ On the contrary, another study comparing thalidomide and ASCT with thalidomide maintenance therapy in previously untreated, elderly patients identified a greater response in the transplant group that was associated with increased side effects and did not improve survival. ${ }^{96}$ Larger studies are required for more conclusive information; this is especially relevant as the majority of myeloma patients are elderly, with a median age of 65 years. ${ }^{94}$

\section{Future therapies}

In spite of many improvements in preparative/maintenance regimens and the accepted benefits of ASCT, there is still a lack of an overall plateau in OS curves and, therefore, a cure per se for myeloma has still not been achieved. This is likely to be due to residual tumor cells and strategies currently under investigation aim to target these.

\section{Allogeneic transplant developments}

The immune-mediated anti-tumor, graft-versus-myeloma (GvM) effect of allogeneic stem cells on the host is one promising area of research arising from the genetic disparity between donor and recipient. However, this is offset by the similarly immune-mediated but problematic GvHD, a significant cause of morbidity.

\section{Donor lymphocyte infusions}

In an attempt to enhance anti-tumor activity, donor lymphocycte infusions (DLI) are undergoing trials which may enhance immune reconstitution and GvM effect. ${ }^{97}$ The GvM effect in response to DLI appears to result from a more global immune reaction, with an antibody response to myeloma-associated antigens. ${ }^{98}$ Adversely, GvHD is increased with DLI, with an incidence of $50 \%$ in one study. ${ }^{99}$ Nevertheless DLI is a promising option warranting further investigation. ${ }^{100}$

\section{Targeting myeloma-specific antigens}

In order to maximize GvM effect and dissociate it from GvHD, tumor specific reactions are being explored. One study identified specific Tcell clones post-DLI in relapsed MM; using PCR they identified a GvM 
effect T-cell population present in low levels before and high levels after DLI, and therefore thought to be donor-derived. ${ }^{101}$ Donor-derived cytotoxic $\mathrm{T}$ cells specific to the myeloma-associated sperm protein 17 have been developed in vitro using antigen-pulsed dendritic cells; these could potentially be administered post-transplant to mediate the GvM effect, avoiding GvHD. ${ }^{102}$ Cancer-testis antigens, which are expressed in more than $55 \%$ of myelomas and not found in healthy bone marrow, are another proposed site for anti-tumor action; antibody responses to these antigens were identified post but not pre-allo-SCT. ${ }^{103}$

\section{Allo-stem cell transplantation and autologous hematopoietic stem cell transplantation vaccine therapies}

Vaccines, using myeloma-specific proteins isolated from host plasma prior to stem cell harvest to induce tumor specific donor T-cell responses have been studied in small clinical trials. One such trial observed good response and survival rates in surviving recipients; although numbers were small, this is a promising strategy and appears to be safe and feasible. ${ }^{104}$

Vaccine therapy is also being explored in ASCT as a consolidative therapy. A small case-control study formed a vaccine by incubating autologous antigen-presenting cells, including dendritic cells, with autologous serum containing myeloma proteins collected pre-transplant. They found improved $\mathrm{OS}$ in those receiving the vaccine. ${ }^{105}$

\section{Monoclonal antibodies in multiple myeloma}

Currently confined to mainly pre-clinical studies, this therapy shows promise for the future. A recent review summarizes potential targets, particularly $2 \mathrm{~m}$, which are present in tumor cells or the surrounding bone marrow environment, or play a role in the interaction between these components. ${ }^{106}$

\section{Conclusions}

The benefits of ASCT as part of a treatment plan for myeloma in young and increasingly older patients are well recognized. Tandem transplantation plays a role, particularly when $1^{\text {st }}$ transplant does not achieve an adequate response. Timing is another important factor in the context of both $1^{\text {st }}$ and $2^{\text {nd }}$ SCT: it is an ongoing debate as to whether these should be administered upfront or as salvage therapy in eligible patients. The latter point becomes particularly relevant with the development of better induction regimens which improve response rates pre-transplant; it has even been proposed that these may reduce the need for front-line transplants altogether. ${ }^{107}$ Allo-SCT is still only used in the context of clinical trials, but these studies have clarified many potential immunotherapy strategies. Consolidation treatment post-SCT improves CR/nCR and PFS. Molecular targets have also been identified through studies of prognostic markers. Novel targeted therapies which include vaccines, explored in both allo-SCT and, more recently ASCT, and monoclonal antibodies aim to address the ongoing problem of recurrent relapse in myeloma patients in spite of all standard treatment currently in use. Larger, randomized, prospective clinical trials are required, and longer follow up is also imperative, as many outcomes will only become apparent after many years.

\section{References}

1. Altekruse SF, Kosary C, Krapcho M, et al. SEER Cancer Statistics Review, 1975-2007, National Cancer Institute, Bethesda, MD. http://seer.cancer.gov/csr/1975_2009_pops09/index.html

2. Ludwig H, Durie BG, Bolejack V, et al. Myeloma in patients younger than age 50 years presents with more favorable features and shows better survival: an analysis of 10549 patients from the International Myeloma Working Group. Blood 2008;111:4039-47.

3. Kim JS, Kim K, Cheong JW, et al. Complete remission status before autologous stem cell transplantation is an important prognostic factor in patients with multiple myeloma undergoing upfront single autologous transplantation. Biol Blood Marrow Transplant 2009;15:463-70.

4. Barlogie B, Jagannath S, Vesole DH, et al. Superiority of tandem autologous transplantation over standard therapy for previously untreated multiple myeloma. Blood 1997;89:789-93.

5. Harousseau JL, Avet-Loiseau H, Attal M, et al. Achievement of at least very good partial response is a simple and robust prognostic factor in patients with multiple myeloma treated with high-dose therapy: long-term analysis of the IFM 99-02 and 99-04 Trials. J Clin Oncol 2009;27:5720-6.

6. Attal M, Harousseau JL, Stoppa AM, et al. A prospective, randomized trial of autologous bone marrow transplantation and chemotherapy in multiple myeloma. Intergroupe Français du Myélome. N Engl J Med 1996;335:91-7.

7. Brenner H, Gondos A, Pulte D. Recent major improvement in longterm survival of younger patients with multiple myeloma. Blood 2008;111:2521-6.

8. Moreau P, Avet-Loiseau H, Harousseau JL, et al. Current trends in autologous stem-cell transplantation for myeloma in the era of novel therapies. J Clin Oncol 2011;29:1898-906.

9. Bladé J, Rosiñol L. Refining "total therapy" for myeloma. Blood 2010;115:4152-3.

10. Gay F, Oliva S, Crippa C, et al. Lenalidomide as post transplant consolidation-maintenance therapy in elderly multiple myeloma patients: updated results of a phase II study. Haematologica (IMW Annual Meeting) 2011;96:S85. (Poster Session ABSTRACT).

11. Cavo M, Rajkumar SV, Palumbo A, et al. International Myeloma Working Group consensus approach to the treatment of multiple myeloma patients who are candidates for autologous stem cell transplantation. Blood 2011;117:6063-73.

12. Rajkumar SV, Blood E, Vesole D, et al. Phase III clinical trial of thalidomide plus dexamethasone compared with dexamethasone alone in newly diagnosed multiple myeloma: a clinical trial coordinated by the Eastern Cooperative Oncology Group. J Clin Oncol 2006;24:431-6.

13. Morgan GJ, Davies FE, Gregory WM, et al. National Cancer Research Institute Haematological Oncology Clinical Studies Group. Cyclophosphamide, thalidomide, and dexamethasone as induction therapy for newly diagnosed multiple myeloma patients destined for autologous stem-cell transplantation: MRC Myeloma IX randomized trial results. Haematologica 2012;97:442-50.

14. Lokhorst HM, Van der Holt B, Zweegman S, et al. A randomized phase 3 study on the effect of thalidomide combined with adriamycin, dexamethasone, and high-dose melphalan, followed by thalidomide maintenance in patients with multiple myeloma. Blood 2010;115:1113-20.

15. Harousseau JL, Attal M, Avet-Loiseau H, et al. Bortezomib plus dexamethasone is superior to vincristine plus doxorubicin plus dexamethasone as induction treatment prior to autologous stemcell transplantation in newly diagnosed multiple myeloma: results of the IFM 2005-01 phase III trial. J Clin Oncol 2010;28:4621-9.

16. Cavo M, Tacchetti P, Patriarca F, et al. Bortezomib with thalidomide plus dexamethasone compared with thalidomide plus dexamethasone as induction therapy before, and consolidation therapy after, double autologous stem-cell transplantation in newly diagnosed multiple myeloma: a randomised phase 3 study. Lancet 


\section{0;376:2075-85.}

17. Rosiñol L, Cibeira MT, Martínez J, et al. Thalidomide/ Dexamethasone (TD) vs. Bortezomib (Velcade $\left.{ }^{\circledR}\right) /$ Thalidomide/dexamethasone (VTD) vs. VBMCP/NBAD/Velcade as induction regimens prior autologous stem cell transplantation (ASCT) in multiple myeloma (MM): results of a phase III PETHEMA/GEM. Blood (ASH Annual Meeting) 2009;114:59.

18. Moreau P, Avet-Loiseau H, Facon T, et al. Bortezomib plus dexamethasone versus reduced-dose bortezomib, thalidomide plus dexamethasone as induction treatment before autologous stem cell transplantation in newly diagnosed multiple myeloma. Blood 2011;118:5752-8.

19. Chanan-Khan AA, Giralt S. Importance of achieving a complete response in multiple myeloma, and the impact of novel agents. J Clin Oncol 2010;28:2612-24.

20. Rajkumar SV, Hayman S, Gertz MA, et al. Combination therapy with thalidomide plus dexamethasone for newly diagnosed myeloma. J Clin Oncol 2002;20:4319-23.

21. Cavo M, Zamagni E, Tosi P, et al. First-line therapy with thalidomide and dexamethasone in preparation for autologous stem cell transplantation for multiple myeloma. Haematologica 2004;89: $826-31$.

22. Cavo M, Di Raimondo F, Zamagni E, et al. Short-term thalidomide incorporated into double autologous stem-cell transplantation improves outcomes in comparison with double autotransplantation for multiple myeloma. J Clin Oncol 2009;27:5001-7.

23. Macro M, Divine M, Uzunhan Y, et al. Dexamethasone+ Thalidomide (Dex/Thal) Compared to VAD as a Pre-Transplant Treatment in Newly Diagnosed Multiple Myeloma (MM): A Randomized Trial. Blood (ASH Annual Meeting) 2006;108:57.

24. Pineda-Roman M, Zangari M, Haessler J, et al. Sustained complete remissions in multiple myeloma linked to bortezomib in total therapy 3: comparison with total therapy 2 . Br J Haematol 2008; $140: 625-34$

25. Nooka A. The Improved Efficacy of Bortezomib Containing Induction Regimens (BCIR) Versus Non-Bortezomib Containing Induction Regimens (NBCIR) in Transplant-Eligible Patients with Multiple Myeloma (MM): Meta-Analysis of Phase III Randomized Controlled Trials (RCTs). Blood (ASH Annual Meeting) 2011;118:3994.

26. Richardson PG, Weller E, Lonial S, et al. Lenalidomide, bortezomib, and dexamethasone combination therapy in patients with newly diagnosed multiple myeloma. Blood 2010;116:679-86.

27. Jakubowiak AJ, Griffith KA, Reece DE, et al. Lenalidomide, bortezomib, pegylated liposomal doxorubicin, and dexamethasone in newly diagnosed multiple myeloma: a phase 1/2 Multiple Myeloma Research Consortium trial. Blood 2011;118:535-43.

28. Kumar S, Flinn I, Richardson PG, et al. Randomized, multicenter, phase 2 study (EVOLUTION) of combinations of bortezomib, dexamethasone, cyclophosphamide, and lenalidomide in previously untreated multiple myeloma. Blood 2012;119:4375-82.

29. Barlogie B, Alexanian R, Dicke KA, et al. High-dose chemoradiotherapy and autologous bone marrow transplantation for resistant multiple myeloma. Blood 1987;70:869-72.

30. Dimopoulos MA, Alexanian R, Przepiorka D, et al. Thiotepa, busulfan, and cyclophosphamide: a new preparative regimen for autologous marrow or blood stem cell transplantation in high-risk multiple myeloma. Blood 1993;82:2324-8.

31. Moreau P, Facon T, Attal M, et al. Comparison of $200 \mathrm{mg} / \mathrm{m}(2) \mathrm{mel}-$ phalan and 8 Gy total body irradiation plus $140 \mathrm{mg} / \mathrm{m}(2)$ melphalan as conditioning regimens for peripheral blood stem cell transplantation in patients with newly diagnosed multiple myeloma: final analysis of the Intergroupe Francophone du Myélome 9502 randomized trial. Blood 2002;99:731-5.
32. Roussel M, Moreau P, Huynh A, et al. Bortezomib and high-dose melphalan as conditioning regimen before autologous stem cell transplantation in patients with de novo multiple myeloma: a phase 2 study of the Intergroupe Francophone du Myelome (IFM). Blood 2010;115:32-7.

33. Ria R, Falzetti F, Ballanti S, et al. Melphalan versus melphalan plus busulphan in conditioning to autologous stem cell transplantation for low-risk multiple myeloma. Hematol J 2004;5:118-22.

34. Lahuerta JJ, Mateos MV, Martínez-López J, et al. Busulfan 12 $\mathrm{mg} / \mathrm{kg}$ plus melphalan $140 \mathrm{mg} / \mathrm{m} 2$ versus melphalan $200 \mathrm{mg} / \mathrm{m} 2$ as conditioning regimens for autologous transplantation in newly diagnosed multiple myeloma patients included in the PETHEMA/GEM2000 study. Haematologica 2010;95:1913-20.

35. Gasparetto C, Bacon W, Doan P, et al. High Dose BCNU/Melphalan Preparative Regimen Doubles Event Free Survival of Myeloma Patients Undergoing Autologous Transplantation. Blood 2011;118:2012.

36. Faber E, Loberiza F Jr, Akhtari M, et al. A Retrospective Analysis Comparing BEAM Versus Melphalan Prior to First Autologous Peripheral Blood Hematopoietic Stem Cell Transplant in Newly Diagnosed Multiple Myeloma Patients. Blood (ASH Annual Meeting) 2011;118:2040 .

37. Cavo M, Tosi P, Zamagni E, et al. Prospective, randomized study of single compared with double autologous stem-cell transplantation for multiple myeloma: Bologna 96 clinical study. J Clin Oncol 2007;25:2434-41.

38. Attal M, Harousseau JL, Facon T, et al. Single versus double autologous stem-cell transplantation for multiple myeloma. $\mathrm{N}$ Engl J Med. 2003;349:2495-502. Erratum in: N Engl J Med 2004;350:2628.

39. Björkstrand B, Iacobelli S, Hegenbart U, et al. Tandem autologous/reduced-intensity conditioning allogeneic stem-cell transplantation versus autologous transplantation in myeloma: longterm follow-up. J Clin Oncol 2011;29:3016-22.

40. Bruno B, Rotta M, Patriarca F, et al. A comparison of allografting with autografting for newly diagnosed myeloma. $\mathrm{N}$ Engl J Med 2007;356:1110-20.

41. Bruno B, Storer B, Patriarca F, et al. Long-Term Follow up of a Comparison of Non-Myeloablative Allografting with Autografting for Newly Diagnosed Myeloma. Blood (ASH Annual Meeting) 2010;116:525.

42. Lokhorst H, van der Holt B, Cornelissen J, et al. Donor versus no donor comparison of newly diagnosed myeloma patients included in the HOVON 50 multiple myeloma study. Blood 2012 [Epub ahead of print].

43. Rosiñol L, Pérez-Simón JA, Sureda A, et al. A prospective PETHEMA study of tandem autologous transplantation versus autograft followed by reduced-intensity conditioning allogeneic transplantation in newly diagnosed multiple myeloma. Blood 2008;112:35913.

44. Krishnan A, Pasquini MC, Ewell M, et al. Tandem Autologous Hematopoietic Stem Cell Transplants (AuHCT) with or without Maintenance Therapy (auto-auto) Versus Single AuHCT Followed by HLA Matched Sibling Non- Myeloablative Allogeneic HCT (autoallo) for Patients with Standard Risk (SR) Multiple Myeloma (MM): Results From the Blood and Marrow Transplant Clinical Trials Network (BMT CTN) 0102 Trial. Blood (ASH Annual Meeting). 2010;116:41.

45. Krishnan A, Pasquini MC, Logan B, et al. Autologous haemopoietic stem-cell transplantation followed by allogeneic or autologous haemopoietic stem-cell transplantation in patients with multiple myeloma (BMT CTN 0102): a phase 3 biological assignment trial. Lancet Oncol 2011;12:1195-203.

46. Garban F, Attal M, Michallet M, et al. Prospective comparison of autologous stem cell transplantation followed by dose-reduced 
allograft (IFM99-03 trial) with tandem autologous stem cell transplantation (IFM99-04 trial) in high-risk de novo multiple myeloma. Blood 2006;107:3474-80.

47. Moreau P, Garban F, Attal M, et al. Long-term follow-up results of IFM99-03 and IFM99-04 trials comparing nonmyeloablative allotransplantation with autologous transplantation in high-risk de novo multiple myeloma. Blood 2008;112:3914-5.

48. Regelink JC, Van Roessel CHM, Van Galen KPM, et al. Long-Term Follow-Up of Tandem Autologous Stem-Cell Transplantation in Multiple Myeloma. J Clin Oncol (Correspondence) 2010;28:35.

49. Barlogie B, Attal M, Crowley J, et al. Long-term follow-up of autotransplantation trials for multiple myeloma: update of protocols conducted by the intergroupe francophone du myelome, southwest oncology group, and university of arkansas for medical sciences. J Clin Oncol 2010;28:1209-14.

50. Rokicka M, Urbanowska E, Torosian T, et al. Triple transplantation of autologous peripheral blood stem cells each time following conditioning with $100 \mathrm{mg} / \mathrm{m} 2$ of melphalan for multiple myeloma patients in poor performance status. Transplant Proc 2003;35:2352-4

51. Berz D, Colvin GA, McCormack EM, et al. Triple MEL100 therapy in multiple myeloma. Transplant Proc 2009;41:3863-7.

52. Lokhorst H, Einsele H, Vesole D, et al. International Myeloma Working Group consensus statement regarding the current status of allogeneic stem-cell transplantation for multiple myeloma. J Clin Oncol 2010;28:4521-30.

53. Kuruvilla J, Shepherd JD, Sutherland HJ, et al. Long-term outcome of myeloablative allogeneic stem cell transplantation for multiple myeloma. Biol Blood Marrow Transplant 2007;13:925-31.

54. Björkstrand BB, Ljungman P, Svensson H, et al. Allogeneic bone marrow transplantation versus autologous stem cell transplantation in multiple myeloma: a retrospective case-matched study from the European Group for Blood and Marrow Transplantation. Blood 1996;88:4711-8.

55. Crawley C, Iacobelli S, Björkstrand B, et al. Reduced-intensity conditioning for myeloma: lower nonrelapse mortality but higher relapse rates compared with myeloablative conditioning. Blood 2007;109:3588-94.

56. Stadtmauer EA, Krishnan A, Pasquini MC, et al. Tandem Autologous Stem Cell Transplants (auto-auto) with or without Maintenance Therapy Versus Single Autologous Transplant Followed by HLA-Matched Sibling Non- Myeloablative Allogeneic Stem Cell Transplant (auto-allo) for Patients (pts) with High Risk (HR) Multiple Myeloma (MM): Results From the Blood and Marrow Transplant Clinical Trials Network (BMT-CTN)0102 Trial. Blood (ASH Annual Meeting) 2010;116:526.

57. Bashey A, Pérez WS, Zhang MJ, et al. Comparison of twin and autologous transplants for multiple myeloma. Biol Blood Marrow Transplant 2008;14:1118-24.

58. Gahrton G, Svensson H, Björkstrand B, et al. Syngeneic transplantation in multiple myeloma - a case-matched comparison with autologous and allogeneic transplantation. European Group for Blood and Marrow Transplantation. Bone Marrow Transplant 1999;24:741-5.

59. Fermand JP, Ravaud P, Chevret S, et al. High-dose therapy and autologous peripheral blood stem cell transplantation in multiple myeloma: up-front or rescue treatment? Results of a multicenter sequential randomized clinical trial. Blood 1998;92:3131-6.

60. Siegel D, Jacobus S, Rajkumar V, et al. Outcome with Lenalidomide Plus Dexamethasone Followed by Early Autologous Stem Cell Transplantation In the ECOG E4A03 Randomized Clinical Trial. Blood (ASH Annual Meeting) 2010;116:38.

61. Palumbo A, Cavallo F, Hardan I, et al. Melphalan/ Prednisone/Lenalidomide (MPR) Versus High-Dose Melphalan and Autologous Transplantation (MEL200) in Newly Diagnosed Multiple Myeloma (MM) Patients <65 Years: Results of a Randomized Phase III Study. Blood (ASH Annual Meeting) 2011;118:3069.

62. Elice F, Raimondi R, Tosetto A, et al. Prolonged overall survival with second on-demand autologous transplant in multiple myeloma. Am J Hematol 2006;81:426-31.

63. Durie BGM, Harousseau J-L, Miguel JS, et al. International uniform response criteria for multiple myeloma. Leukemia 2006;20:1467-73.

64. Ladetto M, Pagliano G, Ferrero S, et al. Major tumor shrinking and persistent molecular remissions after consolidation with bortezomib, thalidomide, and dexamethasone in patients with autografted myeloma. J Clin Oncol 2010;28:2077-84.

65. Cavo M, Pantani L, Petrucci MT, et al. Bortezomib-thalidomidedexamethasone is superior to thalidomide-dexamethasone as consolidation therapy following autologous hematopoietic stemcell transplantation in patients with newly diagnosed multiple myeloma. Blood 2012 [Epub ahead of print].

66. Ludwig H, Durie BG, McCarthy P, et al. (International Myeloma Working Group) IMWG consensus on maintenance therapy in multiple myeloma. Blood 2012;119:3003-15.

67. Attal M, Harousseau JL, Leyvraz S, et al. Maintenance therapy with thalidomide improves survival in patients with multiple myeloma. Blood 2006;108:3289-94.

68. Spencer A, Prince HM, Roberts AW, et al. Consolidation therapy with low-dose thalidomide and prednisolone prolongs the survival of multiple myeloma patients undergoing a single autologous stem-cell transplantation procedure. J Clin Oncol 2009;27:1788-93.

69. Morgan GJ, Gregory WM, Davies FE, et al. The role of maintenance thalidomide therapy in multiple myeloma: MRC Myeloma IX results and meta-analysis. Blood 2012;119:7-15.

70. Attal M, Lauwers-Cances V, Marit G, et al. Lenalidomide Maintenance after Stem-Cell Transplantation for Multiple Myeloma. N Engl J Med 2012;366:1782-91.

71. McCarthy PL, Owzar K, Anderson KC, et al. Phase III Intergroup study of lenalidomide versus placebo maintenance therapy following single autologous hematopoietic stem cell transplantation (AHSCT) for multiple myeloma (MM): CALGB ECOG BMT-CTN 100104. Haematologica (IMW Annual Meeting) 2011;96.

72. McCarthy PL, Owzar K, Hofmeister CC, et al. Lenalidomide after stem-cell transplantation for multiple myeloma. $\mathrm{N}$ Engl $\mathrm{J}$ Med 2012;366:1770-81.

73. Sonneveld P, Schmidt-Wolf I, van der Holt B, et al. HOVON65/GMMG-HD4 randomized phase III trial comparing bortezomib, doxorubicin, dexamethasone (PAD) vs VAD followed by high-dose melphalan (HDM) and maintenance with bortezomib or thalidomide in patients with newly diagnosed multiple myeloma (MM). Blood (ASH Annual Meeting) 2011;116:40.

74. Barlogie B, Kyle RA, Anderson KC, et al. Standard chemotherapy compared with high-dose chemoradiotherapy for multiple myeloma: final results of phase III US Intergroup Trial S9321. J Clin Oncol. 2006;24:929-36. Erratum in: J Clin Oncol 2006;24:2687.

75. Nooka AK.Thalidomide As Maintenance Therapy in Multiple Myeloma (MM) Improves Progression Free Survival (PFS) and Overall Survival (OS): A Meta-Analysis. Blood (ASH Annual Meeting) 2011;118.

76. Ludwig H, Fritz E. Interferon in multiple myeloma--summary of treatment results and clinical implications. Acta Oncol 2000; 39:815-21.

77. Björkstrand B, Goldstone AH, Ljungman P, et al. Prognostic factors in autologous stem cell transplantation for multiple myeloma: an EBMT Registry Study. European Group for Bone Marrow Transplantation. Leuk Lymphoma 1994;15:265-72. 
78. Abraham R, Chen C, Tsang R, et al. Intensification of the stem cell transplant induction regimen results in increased treatmentrelated mortality without improved outcome in multiple myeloma. Bone Marrow Transplant 1999;24:1291-7.

79. Efebera YA, Qureshi SR, Cole SM, et al. Reduced-intensity allogeneic hematopoietic stem cell transplantation for relapsed multiple myeloma. Biol Blood Marrow Transplant 2010;16:1122-9.

80. Soverini S, Cavo M, Cellini C, et al. Cyclin D1 overexpression is a favorable prognostic variable for newly diagnosed multiple myeloma patients treated with high-dose chemotherapy and single or double autologous transplantation. Blood 2003;102:1588-94.

81. Rotta M, Storer BE, Sahebi F, et al. Long-term outcome of patients with multiple myeloma after autologous hematopoietic cell transplantation and nonmyeloablative allografting. Blood 2009;113: 3383-91.

82. Kim SY, Min HJ, Park HK, et al. Increased copy number of the interleukin-6 receptor gene is associated with adverse survival in multiple myeloma patients treated with autologous stem cell transplantation. Biol Blood Marrow Transplant 2011;17:810-20.

83. Joshua D, Petersen A, Brown R, et al. The labelling index of primitive plasma cells determines the clinical behaviour of patients with myelomatosis. Br J Haematol1996;94:76-81.

84. Rosiñol L, Oriol A, Mateos MV, et al. Phase II PETHEMA trial of alternating bortezomib and dexamethasone as induction regimen before autologous stem-cell transplantation in younger patients with multiple myeloma: efficacy and clinical implications of tumor response kinetics. J Clin Oncol 2007;25:4452-8.

85. Gutiérrez NC, Castellanos MV, Martín ML, et al. Prognostic and biological implications of genetic abnormalities in multiple myeloma undergoing autologous stem cell transplantation: $t(4 ; 14)$ is the most relevant adverse prognostic factor, whereas RB deletion as a unique abnormality is not associated with adverse prognosis. Leukemia 2007;21:143-50.

86. Facon T, Avet-Loiseau H, Guillerm G, et al. Chromosome 13 abnormalities identified by FISH analysis and serum beta2-microglobulin produce a powerful myeloma staging system for patients receiving high-dose therapy. Blood 2001;97:1566-71.

87. Qazilbash MH, Saliba RM, Hosing C, et al. Autologous stem cell transplantation is safe and feasible in elderly patients with multiple myeloma. Bone Marrow Transplant 2007;39:279-83.

88. Martino M, Console G, Irrera G, et al. High-dose therapy and autologous peripheral blood stem cells transplantation followed by a very low reduced intensity regimen with fludarabine + cyclophosphamide and allograft improve complete remission rate in de novo multiple myeloma patients. Am J Hematol 2006;81:973-8.

89. Fernández de Larrea C, Tovar N, Rozman M, et al. Multiple myeloma in serologic complete remission after autologous stem cell transplantation: impact of bone marrow plasma cell assessment by conventional morphology on disease progression. Biol Blood Marrow Transplant 2011;17:1084-7.

90. Paiva B, Vidriales MB, Cerveró J, et al. Multiparameter flow cytometric remission is the most relevant prognostic factor for multiple myeloma patients who undergo autologous stem cell transplantation. Blood 2008;112:4017-23.

91. Kim H, Sohn HJ, Kim S, et al. New staging systems can predict prognosis of multiple myeloma patients undergoing autologous peripheral blood stem cell transplantation as first-line therapy. Biol Blood Marrow Transplant 2006;12:837-44.

92. Siegel DS, Desikan KR, Mehta J, et al. Age is not a prognostic vari- able with autotransplants for multiple myeloma. Blood 1999;93:514.

93. Palumbo A, Triolo S, Argentino C, et al. Dose-intensive melphalan with stem cell support (MEL100) is superior to standard treatment in elderly myeloma patients. Blood 1999;94:1248-53.

94. Jantunen E, Kuittinen T, Penttilä K, et al. High-dose melphalan $(200 \mathrm{mg} / \mathrm{m} 2)$ supported by autologous stem cell transplantation is safe and effective in elderly (>or=65 years) myeloma patients: comparison with younger patients treated on the same protocol. Bone Marrow Transplant 2006;37:917-22.

95. Sirohi B, Powles R, Treleaven J, et al. The role of autologous transplantation in patients with multiple myeloma aged 65 years and over. Bone Marrow Transplant 2000;25:533-9.

96. Offidani M, Leoni P, Corvatta L, et al. ThaDD plus high dose therapy and autologous stem cell transplantation does not appear superior to ThaDD plus maintenance in elderly patients with de novo multiple myeloma. Eur J Haematol 2010;84:474-83.

97. Bellucci R, Alyea EP, Weller E, et al. Immunologic effects of prophylactic donor lymphocyte infusion after allogeneic marrow transplantation for multiple myeloma. Blood 2002;99:4610-7.

98. Bellucci R, Wu CJ, Chiaretti S, et al. Complete response to donor lymphocyte infusion in multiple myeloma is associated with antibody responses to highly expressed antigens. Blood 2004;103:65663.

99. Alyea E, Weller E, Schlossman R, et al. T-cell--depleted allogeneic bone marrow transplantation followed by donor lymphocyte infusion in patients with multiple myeloma: induction of graft-versusmyeloma effect. Blood 2001;98:934-9.

100. Levenga $H$, Levison-Keating S, Schattenberg AV, et al. Multiple myeloma patients receiving pre-emptive donor lymphocyte infusion after partial T-cell-depleted allogeneic stem cell transplantation show a long progression-free survival. Bone Marrow Transplant 2007;40:355-9.

101. Orsini E, Bellucci R, Alyea EP, et al. Expansion of tumor-specific CD8+ T cell clones in patients with relapsed myeloma after donor lymphocyte infusion. Cancer Res 2003;63:2561-8.

102. Chiriva-Internati M, Wang Z, Xue Y, et al. Sperm protein 17 (Sp17) in multiple myeloma: opportunity for myeloma-specific donor $\mathrm{T}$ cell infusion to enhance graft-versus-myeloma effect without increasing graft-versus-host disease risk. Eur J Immunol 2001;31:2277-83.

103. Atanackovic D, Arfsten J, Cao Y, et al. Cancer-testis antigens are commonly expressed in multiple myeloma and induce systemic immunity following allogeneic stem cell transplantation. Blood 2007;109:1103-12.

104. Neelapu SS, Munshi NC, Jagannath S, et al. Tumor antigen immunization of sibling stem cell transplant donors in multiple myeloma. Bone Marrow Transplant 2005;36:315-23.

105. Lacy MQ, Mandrekar S, Dispenzieri A, et al. Idiotype-pulsed antigen-presenting cells following autologous transplantation for multiple myeloma may be associated with prolonged survival. Am J Hematol. 2009;84:799-802. Erratum in: Am J Hematol 2010;85:309.

106. Yang J, Yi Q. Therapeutic monoclonal antibodies for multiple myeloma: an update and future perspectives. Am J Blood Res 2011;1:22-33.

107. El Cheikh J, Kfoury E, Calmels B, et al. Age at transplantation and outcome after autologous stem cell transplantation in elderly patients with multiple myeloma. Hematol Oncol Stem Cell Ther 2011;4:30-6. 